\title{
Lumbar mechanical traction: a biomechanical assessment of change at the lumbar spine
}

\author{
Shigeru Tadano ${ }^{1,7}$, Hideki Tanabe ${ }^{2}$, Sadao Arai ${ }^{3}$, Keiji Fujino ${ }^{4}$, Tokuhide Doi ${ }^{5,8}$ and Masami Akai ${ }^{6^{*}}$ (D)
}

\begin{abstract}
Background: Lumbar traction is a traditional treatment modality for chronic low back pain (CLBP) in many countries. However, its effectiveness has not been demonstrated in clinical practice because of the following: (1) the lack of in vivo biomechanical confirmation of the mechanism of lumbar traction that occurs at the lumbar spine; (2) the lack of a precise delivery system for traction force and, subsequently, the lack of reproducibility; and (3) few randomized controlled trials proving its effectiveness and utility.
\end{abstract}

Methods: This study was planned as a preparatory experiment for a randomized clinical trial, and it aimed (1) to examine the biomechanical change at the lumbar area under lumbar traction and confirm its reproducibility and accuracy as a mechanical intervention, and (2) to reconfirm our clinical impression of the immediate effect of lumbar traction. One hundred thirty-three patients with non-specific CLBP were recruited from 28 orthopaedic clinics to undergo a biomechanical experiment and to assess and determine traction conditions for the next clinical trial. We used two types of traction devices, which are commercially available, and incorporated other measuring tools, such as an infrared range-finder and large extension strain gauge. The finite element method was used to analyze the real data of pelvic girdle movement at the lumbar spine level. Self-report assessments with representative two conditions were analyzed according to the qualitative coding method.

Results: Thirty-eight participants provided available biomechanical data. We could not measure directly what happened in the body, but we confirmed that the distraction force lineally correlated with the movement of traction unit at the pelvic girdle. After applying vibration force to preloading, the strain gauge showed proportional vibration of the shifting distance without a phase lag qualitatively. FEM simulation provided at least 3.0-mm shifting distance at the lumbar spine under $100 \mathrm{~mm}$ of body traction. Ninety-five participants provided a treatment diary and were classified as no pain, improved, unchanged, and worsened. Approximately 83.2\% of participants reported a positive response.

Conclusion: Lumbar traction can provide a distractive force at the lumbar spine, and patients who experience the application of such force show an immediate response after traction.

Trial registration: University Hospital Medical Information Network - Clinical Trial Registration: UMIN-CTR000024329 (October 13, 2016).

Keywords: Chronic low back pain, Lumbar traction, Biomechanical experiment, Finite element method, Traction conditions, Traction stiffness

\footnotetext{
* Correspondence: akai-masami@iuhw.ac.jp

${ }^{6}$ Graduate School, International University of Health and Welfare, 4-1-26

Akasaka, Minato-ku, Tokyo 107-8402, Japan

Full list of author information is available at the end of the article
}

(c) The Author(s). 2019 Open Access This article is distributed under the terms of the Creative Commons Attribution 4.0 International License (http://creativecommons.org/licenses/by/4.0/), which permits unrestricted use, distribution, and reproduction in any medium, provided you give appropriate credit to the original author(s) and the source, provide a link to the Creative Commons license, and indicate if changes were made. The Creative Commons Public Domain Dedication waiver (http://creativecommons.org/publicdomain/zero/1.0/) applies to the data made available in this article, unless otherwise stated. 


\section{Background}

Chronic low back pain (LBP) is a common and major source of distress and disability among working individuals in industrialized countries $[1,2]$. In the Japanese population, the prevalence of LBP is highest among other health problems (men: 92.2 per 1000 population; women: 118.2 per 1000 population) according to the statistics by the Ministry of Health, Labour, and Welfare of Japan [3].

Among several conservative treatments for LBP, previous studies have indicated that mechanical lumbar traction is not effective for treating acute LBP [4-6]. A previous systematic review by Wegner et al. concluded that traction, either alone or in combination with other treatments, has little or no impact on pain intensity, functional status, global improvement, and return to work among people with chronic LBP [6]. This finding might be because of (1) the lack of in vivo biomechanical confirmation of the mechanism of lumbar traction that occurs at the lumbar spine; (2) the lack of a precise delivery system for traction force and, subsequently, the lack of reproducibility; and (3) few randomized controlled trials proving the effectiveness and utility of lumbar traction.

However, lumbar traction is still a widely accepted, popular treatment modality for patients with chronic LBP $[7,8]$. Many clinicians and physical therapists continue to use it for chronic nonspecific LBP too. Indeed, expert clinical opinions, theoretical models, and research suggest that certain patients with LBP respond positively to lumbar traction [9-11]. Since many patients with LBP are not indicated for surgical intervention, conservative management for patients with LBP is important in clinical practice. Further evidence is needed to support the effectiveness of lumbar traction.

Supposed beneficial effects of lumbar traction are as follows:

- extension of the soft part tissue around the facet joint,

- displaced correction of the intervertebral discs and facet joint,

- separation of the facet joint,

- expansion in the intervertebral foramen,

- decreased pressure of the intervertebral discs,

- extension of the anterior and posterior longitudinal ligaments around the vertebral body,

- reduction of prolapsed discs,

- relaxation of muscle spasm by stretching,

- improvement of blood circulation, and

- psychological effect.

However, some of these in vivo changes are difficult to prove directly.
Recently, we have been able to use a very sophisticated device for lumbar traction with computerized precise control that provides a stable mechanical condition for each individual. One of the main reasons why we could not achieve definite results of lumbar traction previously could be resolved with such a device.

This study aimed (1) to examine the biomechanical change at the lumbar area under such traction and confirm its reproducibility and accuracy as a mechanical intervention; and (2) to reconfirm our clinical impression of the immediate effect of lumbar traction. As a final research object, we plan to investigate the clinical effectiveness of mechanical lumbar traction on pain, dysfunction, and quality of life in individuals with chronic LBP by performing a randomized controlled trial, and the present study is a preliminary step for this.

\section{Methods}

\section{Study design and setting}

This study consisted of two parts. (1) Biomechanical experiment: We designed a biomechanical experimental system consisting of a biomechanical assessment of distraction status at the lumbar area in patients with LBP, and finite element modeling at the lumbar spine. (2) Clinical qualitative study: We administered a self-report assessment to participants in order to reconfirm the immediate effect of lumbar traction, which is based on our clinical impression, as well as to reconfirm no adverse event.

The current study was part of a comprehensive clinical trial that was registered in the University Hospital Medical Information Network-Clinical Trial Registration (UMIN-CTR 000024329, date opened: October 13, 2016).

\section{Participants}

We recruited participants from six outpatient clinics that used two types of traction devices (MINATO Medical Science, ST-2 L/2CL and OG Wellness Technologies, OL-6500/6000).

\section{Inclusion and exclusion criteria}

The inclusion and exclusion criteria were determined according to a previous clinical trial on chronic LBP [12]. Participants aged 20-65 years who consulted with their orthopedic surgeons because of a complaint of non-specific chronic LBP for more than 3 months' duration; those who were able to give informed written consent; those without neurologic deficits; and those who satisfied the following criteria: angle of more than $70^{\circ}$ during the straight-leg-raising test, negative femoral nerve stretching test result, no superficial sensory deficits, and no muscle weakness less than 4/5 according to the muscle manual testing were enrolled in this study. LBP was defined as pain localized below the L1 spinal 
process and above the inferior gluteal folds without sciatica (radicular pain). Chronological fluctuation of pain was not considered if the pain itself continued for more than 3 months.

Exclusion criteria were patients who had LBP due to tumors, infections, or fractures; previous back surgery; severe osteoporosis; psychiatric disorders, such as depression or others; liver and renal dysfunction; pregnancy; medication for cardiac failure; a history of cerebrovascular accident and/or myocardial infarction within 6 months before the day of agreement to enter the trial; and were not suitable for traction according to the attending physician.

\section{Ethical statements}

Patients' attending physicians provided an information leaflet about the experiment, completed the patient information sheets in order to determine eligibility based on the inclusion and exclusion criteria, and obtained written informed consent to participate from each patient. The institutional review board of the Japanese
Clinical Orthopaedic Association approved the protocol of the present clinical experiment (approval number: 2015-01).

\section{Description of the experiment Device for delivering precise traction force}

We used two types of traction devices that are commercially available as the same category of classification (MINATO Medical Science, ST-2 L/2CL and OG Wellness Technologies, OL-6500/6000). Both device consist of two main parts: the holding part that holds the upper body and the moving part that maintains a uniform $90^{\circ}-90^{\circ}$ position of the lower extremities (Fig. 1). The upper body unit automatically measures the height of the arm pit using an adjustable holding arm to keep the participant in the sitting position. The lower body unit secures the participant in $90^{\circ}$ of hip flexion with a pelvic girdle belt, and the thigh lengths with $90^{\circ}$ flexion of the knee joints is maintained by lifting the shin component. These two main components are moved separately on the rail via an actuator connected to a load cell.
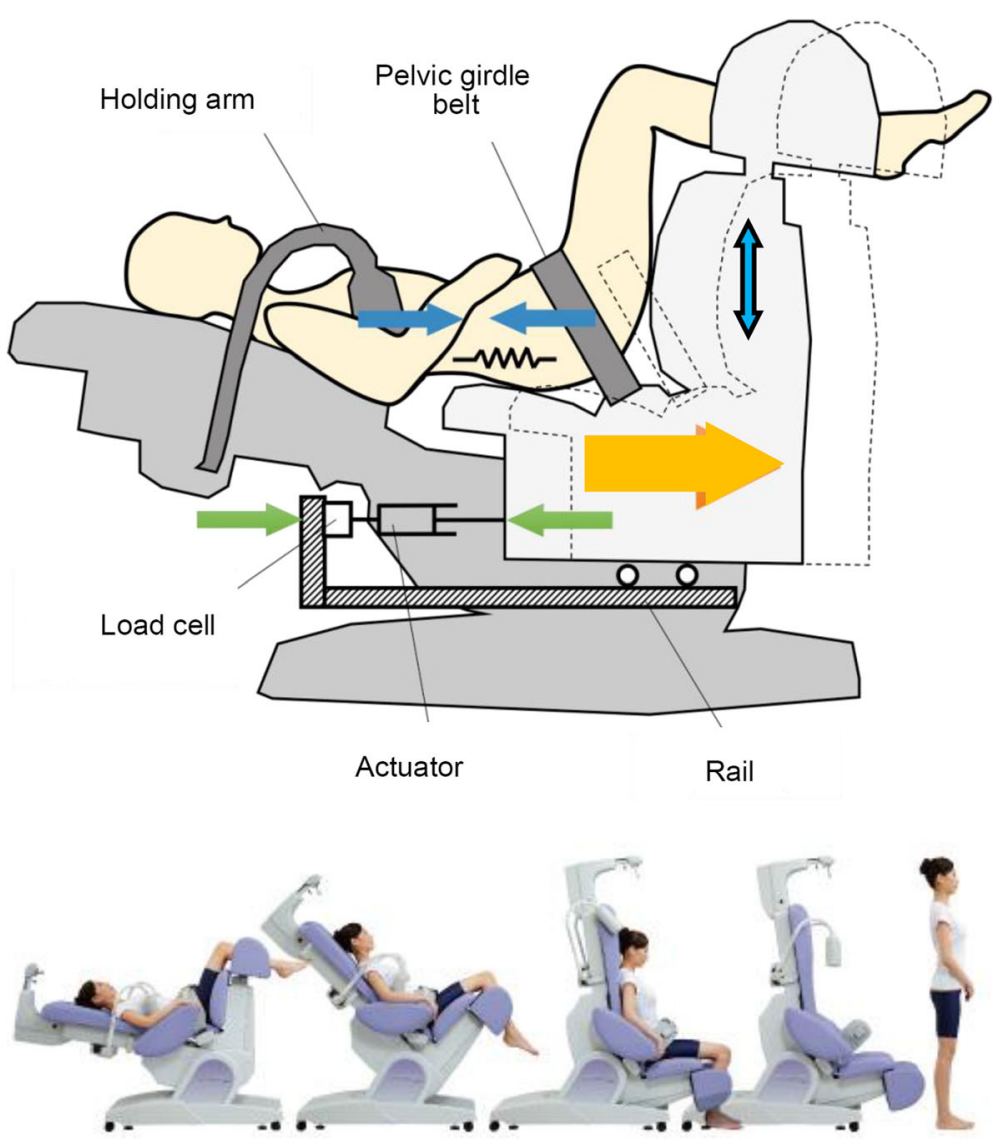

Fig. 1 Drawing schema of the traction device used in this study (the bottom of Fig. 1 is adopted from the pamphlet for the ST-2 L/2CL with permission from MINATO Medical Science). The device consists of two main parts: the holding part that holds the upper body and the moving part that maintains a uniform $90^{\circ}-90^{\circ}$ position of the lower extremities. Serial clinical pictures of the application of lumbar traction using the device (ST-2 L/2CL) 
After the participant laid down on the device, it took $73 \mathrm{~s}$ to start the active traction mode. During this phase, the load cell voltage indicated the same pattern of change in each case.

First, we conducted the biomechanical experiment using the ST-2 L/2CL by incorporating other measuring tools such as an infrared range-finder (SHARP, GP2D12), a strain gauge for large deformation (KYOWA, KFEM-10-120), surface electromyogram (HARADA Electronic, 8-ch EMG Telemeter), electrocardiogram (HARADA Electronic, 8-ch EMG Telemeter), and analog/digital convertor (KYOWA, PCD320A, PCD300A). Figure 2 shows the block diagram of the measuring system. Second, we performed the clinical experiment using the ST-2 $\mathrm{L} / 2 \mathrm{CL}$ and OL-6500/6000 in order to calculate in vivo mechanical stiffness and find the difference in traction modes.

The features of the device were as follows.

(1) The participant's posture during traction was maintained in hip flexion of $90^{\circ}$ with minimal lumbar lordosis of the moving lower body part. The length of the thigh varied in each case and was adjusted by $90^{\circ}$ of knee flexion.
(2) The main measuring systems monitored the movement of the traction unit holding the pelvic girdle belt from two aspects: the loading pattern (measured by the machine itself) and distraction distance (measured by the infrared range-finder). The device delivered a regulated traction force between the two main parts via a feedback mechanism against stress-relaxation due to viscoelastic properties of body tissues.

(3) Upper body holding at the armpit by the adjustable arm worked to counter the lumbar traction.

Technicians who had lecture with the staff of Dr. Tadano's laboratory attended each clinic to add the special devices to the original traction unit. They also supervised the necessary procedures that staff of clinics used to apply the strain gauge system. After exposing the participant's back, the staff cleaned up the skin with alcohol, pasted the strain gauge with glue, and connected the electrical lines. These procedures were performed in the annex room next to where the traction devices were located.

The participants in the biomechanical experiment were subjected to the following.

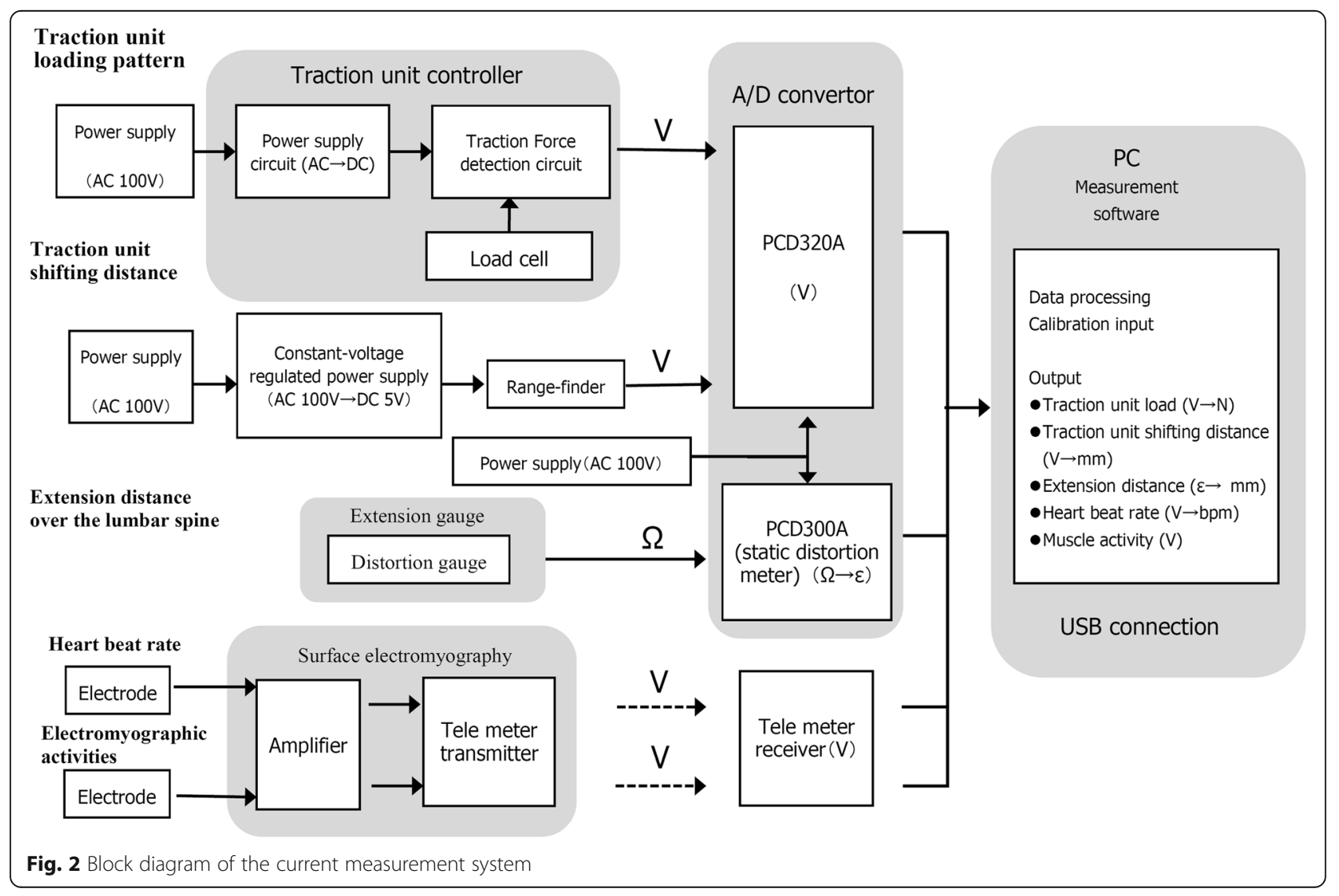


(4) A strain gauge was attached at the surface of their lower back with the help of adhesive glue, and it was connected to a static distortion meter (Fig. 3).

(5) A surface electromyogram at the three levels of both paravertebral muscles and an electrocardiogram were used to confirm participants' relaxation status.

Data generated from these instruments were automatically processed through an analog-todigital convertor and recorded by a computer as synchronized data.

We measured the following parameters with this system: (1) the traction unit loading pattern, (2) traction unit shifting distance; (3) in vivo extension distance at the skin surface over the lumbar spine, (4) heart beat rate, and (5) surface electromyographic activities.

\section{Traction loading pattern}

We set two types of loading patterns as a cross-over design, which were applied randomly, with a towing condition determined according to the most popular method of

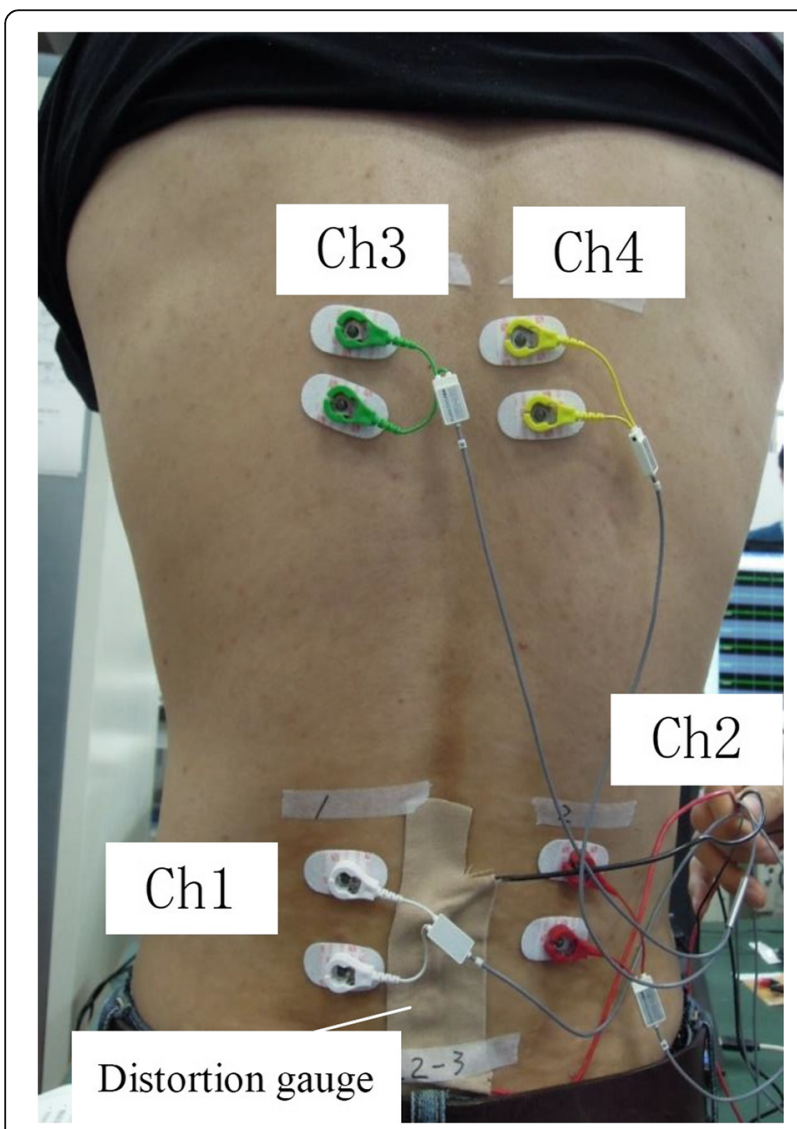

Fig. 3 Photograph of a participant's back. The photograph shows the surface electrodes (Ch. 1-4) for electromyography attached to the paravertebral muscles and the strain gauge attached to the lumbar spine traction used in the present clinical setting (Table 1). We evaluated various experimental conditions as a preliminary study. When we shifted from one towing condition to another one, we allowed at least 20 min of rest as a washout time. In the clinical assessment, at least two days were interposed between the different traction conditions.

For the loads of traction, $40 \%$ of the body weight was used as the preload. Ten minutes was used as the traction treatment time.

Towing A1 = Vibration function at a frequency of 0.1 $\mathrm{Hz}$ was added to the preload (traction for $10 \mathrm{~min}$ ). The vibration amplitude load was $30 \%$ of the preload (amplitude between 100 and 70\%). This traction was repeated for $60 \mathrm{~s}$ and suspension for $10 \mathrm{~s}$.

Towing $\mathrm{A}=$ The vibration amplitude load was $30 \%$ of the preload. This traction was repeated for $30 \mathrm{~s}$ and suspension for $5 \mathrm{~s}$.

Towing A2 = The vibration amplitude load was $20 \%$ of the preload. This traction was repeated for $30 \mathrm{~s}$ and suspension for $5 \mathrm{~s}$.

Towing $\mathrm{B}=$ Traction was applied for $30 \mathrm{~s}$ and suspension for $5 \mathrm{~s}$.

After setting the various measuring systems, we applied one set of trial traction as the adjustment, and then performed towing conditions $\mathrm{A}$ and $\mathrm{B}$ three times each for two weeks.

\section{Maintaining strain gauge and the measuring conditions}

Initially, it was difficult to maintain adhesion of the strain gauge to the skin of the lumbar spine. During distractive application of up to $10 \mathrm{~min}$, some cases failed to maintain the experimental conditions. However, this issue could be controlled for by using tape to reinforce placement of the gauge. Additionally, the electrode wiring clip protruded outside, and there was a possibility that it could come off during towing. During the experiments, the participants wore $t$-shirts so that the electrode parts did not touch the backrest of the towing machine directly. Occasionally, the electrode clip became pulled off during towing and was unable to obtain a measurement, but in most cases, the myoelectric potential was measured without problems.

The traction delivery chart on display showed some perturbation when the participants strained themselves. Electromyographic activities could be a good indicator for relaxation of the body muscles.

The criteria of successive data recording were dependent on the responsiveness of the infrared range-finder, in which the curve shifted to the + side during the traction phase and to the - side during the relaxation phase.

\section{Finite element model simulation}

Computer simulation of deformation at the lumbar spine level under lumbar traction force was performed using FEM software (ANSYS 15.0 ANSYS. Inc.). Musculoskeletal 
Table 1 Baseline characteristics of participants of biomechanical experiment and clinical study

\begin{tabular}{|c|c|c|c|c|c|c|}
\hline & ${ }^{\mathrm{a} D e v i c e s}$ & $\mathrm{~N}$ & $\begin{array}{c}{ }^{\mathrm{b}} \text { Gender } \\
\text { Male: Female }\end{array}$ & $\begin{array}{l}{ }^{\mathrm{b}} \mathrm{Age} \\
\text { (Mean) }\end{array}$ & $\begin{array}{l}\text { Age } \\
\text { (SD) } \\
\end{array}$ & $\begin{array}{l}\text { Towing mode } \\
\text { traction for } 10 \mathrm{mir}\end{array}$ \\
\hline \multirow[t]{4}{*}{ Biomechanical } & $\mathrm{ST}-2 \mathrm{~L} / 2 \mathrm{CL}$ & 14 & $9: 5$ & 35.1 & 11.1 & $A 1, B$ \\
\hline & & 10 & $4: 6$ & 47.7 & 9.7 & $A, B$ \\
\hline & OL-6500/6000 & 7 & $1: 6$ & 44.3 & 11.5 & $A, B$ \\
\hline & & 7 & $3: 4$ & 40.7 & 10.4 & $A, A 2$ \\
\hline net & & 38 & $17: 21$ & 41.1 & 11.7 & \\
\hline \multirow[t]{2}{*}{ Clinical } & $A \rightarrow B$ & 49 & $27: 22$ & 42.2 & 12.6 & $A, B$ \\
\hline & $B \rightarrow A$ & 46 & $19: 27$ & 41.5 & 13.6 & $A, B$ \\
\hline
\end{tabular}

${ }^{a}$ MINATO Medical Science, ST-2 L/2CL and OG Wellness Technologies, OL-6500/6000

Towing $A=$ Vibration amplitude load was $30 \%$ of the preload. It's repeated for traction $30 \mathrm{~s}$ and suspension $5 \mathrm{~s}$

Towing $\mathrm{A} 1=$ Vibration function at the frequency of $0.1 \mathrm{~Hz}$ was added onto the preload. Vibration amplitude load was $30 \%$ of the preload. It's repeated for traction $60 \mathrm{~s}$ and suspension $10 \mathrm{~s}$

Towing A2 = Vibration amplitude load was $20 \%$ of the preload. It's repeated for traction $30 \mathrm{~s}$ and suspension $5 \mathrm{~s}$

Towing $\mathrm{B}=$ Traction $30 \mathrm{~s}$ and suspension $5 \mathrm{~s}$

${ }^{b}$ According to t-test for equality of means between $A \rightarrow B$ and $B \rightarrow A$, age is not significant with mean difference 0.768 (95\% Confidence Interval of the Difference: -4.555 to 6.091$), p=0.775$

Also, in Chi-Square, there was no significant difference of the male: female ratio between $\mathrm{A} \rightarrow \mathrm{B}$ and $\mathrm{B} \rightarrow \mathrm{A}, p=0.179$

modeling of the whole body sitting in the traction device was performed using OpenSim 2.4 (National Center for Simulation in Rehabilitation Research, Stanford University) and CAD software (Geomagic for Solidwork). A whole body skeletal model positioned in the traction device was distorted in the same manner as in clinical treatment.

\section{Treatment diary}

The participants maintained a treatment diary about their conditions after each intervention for two weeks. This diary was requested to confirm that the device operated without any problems and to collect self-report assessments by participants. They provided brief comments about their health status each day in their treatment diary. Since we added a few parts to the commercial products and modified the traction mode, we mainly investigated the patients' perception on the newly introduced condition such as the vibration traction method and whether they experienced any inconveniences.

The participants' perspective on health status before and after lumbar traction, which focused on 6 days of the actual traction trial, was analyzed using a summarized tabulation of their experiences. We used the mixed method with qualitative categorization and quantitative calculation.

An independent researcher read the participants' comments for each day and classified each one into four categories: no pain, improved, unchanged, and worsened. Coding was used to rate the content of the diary over three consecutive days in order to determine a representative health status: " $\mathrm{n}$ " was assigned to no pain, "i" to improved, " $u$ " to unchanged, and " $w$ " to worsened. For example, a figure sequence "uui" meant unchanged unchanged - improved for three days per week.

\section{Statistical analysis}

Biomechanical parameters (mean values) were analyzed with the paired t-test to determine differences between towing modes A group and B. The $95 \%$ confidence interval (CI) of the population mean of the shifting distance, and correlation coefficient between traction stiffness (TS) and age were calculated.

As for the clinical analysis of the treatment diary, the chi-square test was used to determine differences of female-to-male ratio between $\mathrm{A} \rightarrow \mathrm{B}$ and $\mathrm{B} \rightarrow \mathrm{A}$. Other data such as age, height, weight, and body mass index were analyzed using the t-test for equality of means between $\mathrm{A} \rightarrow \mathrm{B}$ and $\mathrm{B} \rightarrow \mathrm{A}$. The Mantel-Haenszel chi-square for $2 \mathrm{x} \mathrm{r}$ tables was used to evaluate the results of the self-report assessments for each traction mode. All statistical analyses were performed with SPSS Statistics 17.0 for Windows (SPSS Inc.).

Statement of the location where the work was performed The biomechanical research including FEM simulation was performed in the laboratory of Bio-Mechanical Design, Division of Human Mechanical Systems and Design, Faculty of Engineering, Hokkaido University, and six orthopedic clinics.

The clinical study was conducted in 28 orthopedic clinics (see acknowledgements).

\section{Results}

Available data acquisition

For the biomechanical experiment, 38 adults aged 2059 years from six orthopedic clinics participated. The ST-2 L/2CL was used in 24 cases and OL-6500/6000 in 14 cases that provided biomechanical data for calculating stiffness and others. The remaining participants 
submitted their clinical assessment of the effectiveness of lumbar traction to determine the optimal traction condition (Table 1).

Subsequently, we collected biomechanical data from 14 cases for A1 mode, 24 for A, 31 for B, and 7 for A2. The strain data were also available for 14 cases for A1 mode, 8 for A, 22 for B, and 4 for A2 (Figs. 4 and 5).

For the clinical experiment, $\mathrm{A}$ to $\mathrm{B}$ traction assignment consisted of 49 cases, whereas B to A consisted of 46 cases. We collected 570 health status assessment codes, each after traction condition and converted them into 190 cases with coding of diary content for three consecutive
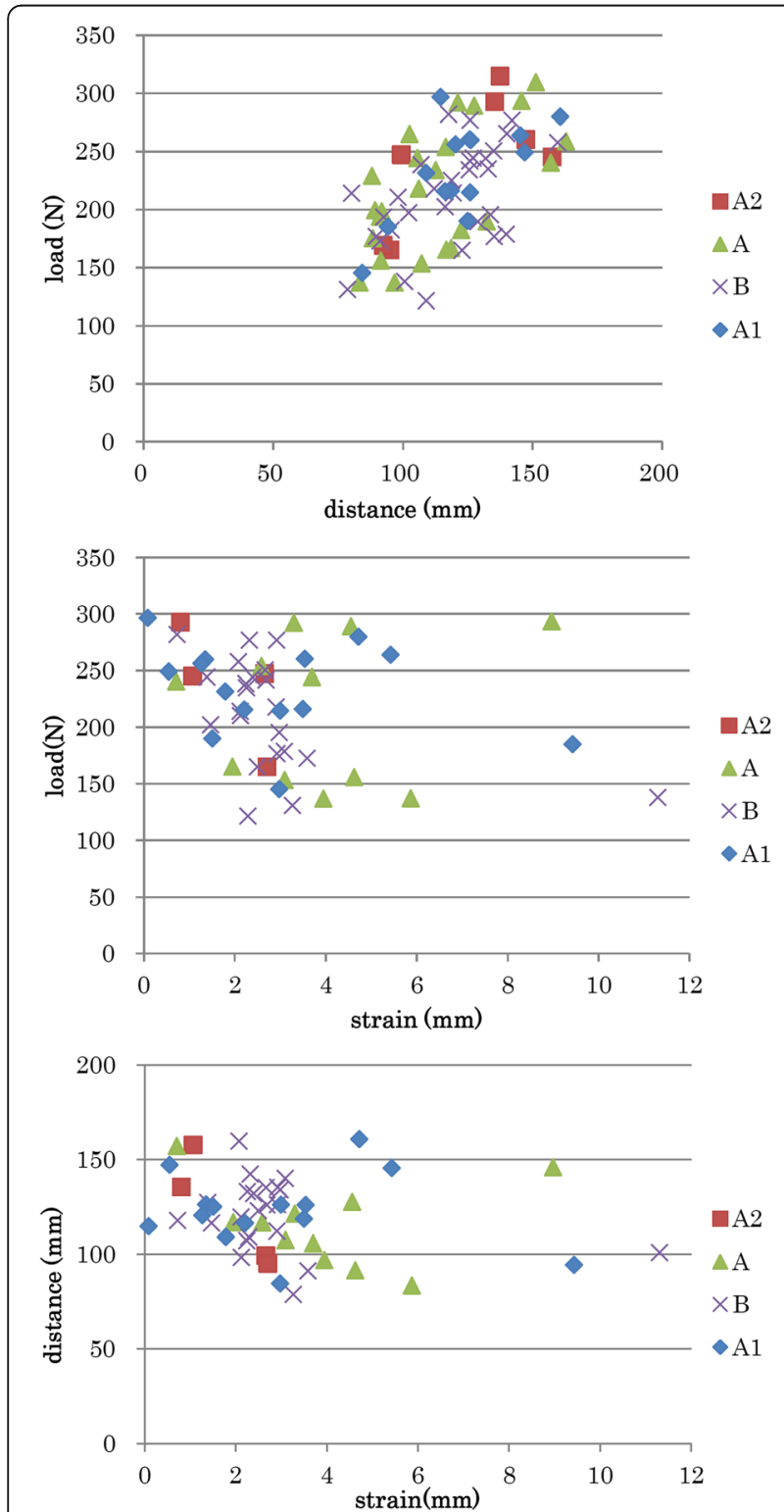

Fig. 4 Graphic results of biomechanical measurement. Although there is a proportional relationship between load and distance (i, e., traction stiffness), the relationship between load and strain gauge or between distance and strain gauge is unclear days. Typical comments in the diary were as follows: "I feel so much better," "The pain was relieved," "My back got lighter," "It got easier to move," and "The numbness became light." The results are shown in Table 2 .

\section{Results of each parameter}

The $95 \%$ CIs of the population mean of the distance of the traction unit were $110.9-134.0 \mathrm{~mm}$ in A1 mode, 110.1$124.6 \mathrm{~mm}$ in $\mathrm{B}, 103.9-123.5 \mathrm{~mm}$ in $\mathrm{A}$, and $98.5-148.8 \mathrm{~mm}$ in A2. The 95\% CIs of the strain gauge distance were $1.6-$ $4.3 \mathrm{~mm}$ in A1 mode, $2.6-6.7 \mathrm{~mm}$ in $\mathrm{A}$, and $1.9-3.7 \mathrm{~mm}$ in $\mathrm{B}$.

The strain gauge was able to determine the linear response to vibration movement at the skin surface of the lumbar spine during the first step. However, it was difficult to quantify the data of the strain gauge, which may be due to the variations in each subject as well as the viscoelasticity of tissue around the armpit or pelvic girdle at the body holding and other sites that masked the actual fluctuation of living tissue.

\section{Traction stiffness}

TS $(\mathrm{N} / \mathrm{mm})$ were calculated using the first peak value of distractive load and shifting distance. In towing A1 with the ST-2 L/2CL, the TS value was $1.96 \pm 0.34 \mathrm{~N} / \mathrm{mm}$ (average value $[\mathrm{AV}] \pm$ standard deviation $[\mathrm{SD}]$ ), and it was $2.09 \pm 0.11 \mathrm{~N} / \mathrm{mm}$ in towing A with the OL-6500/ 6000. In towing $B$, the TS values were $2.00 \pm 0.35 \mathrm{~N} / \mathrm{mm}$ and $1.94 \pm 0.29 \mathrm{~N} / \mathrm{mm}$ with the ST-2 L/2CL and OL-6500/6000, respectively. There was no statistically significant difference between the two devices $(p=0.430$ and $p=0.656$, t-test). There was no relationship between TS and age, as indicated in towing conditions A1 $(r=-$ $0.175)$, A $(r=-0.300)$, and $B(r=-0.075)$.

In the intra-participant comparison, however, the TS value in towing $\mathrm{A} 1$ was $1.93 \pm 0.09 \mathrm{~N} / \mathrm{mm}(\mathrm{AV} \pm \mathrm{SD})$, and it was $1.83 \pm 0.08 \mathrm{~N} / \mathrm{mm}$ in towing $\mathrm{B}$ ( $p=0.001$, paired t-test). The TS value in towing $A$ was $2.09 \pm 0.11 \mathrm{~N} / \mathrm{mm}$, and it was $1.87 \pm 0.05 \mathrm{~N} / \mathrm{mm}$ in towing $B(p=0.080$, paired t-test). There was no difference between towing conditions $\mathrm{A}$ and A2 $(p=0.231$, paired $t$-test). In each participant, the difference of traction mode produced distinct responses.

\section{Finite element method simulation}

In FEM stimulation, when the kyphosis of the entire spine is fixed to the shoulder and the pelvis are under the same condition as the present device, and towing distance is 100 $\mathrm{mm}$, the lumbar region (L1-5) becomes targeted part under distraction. To confirm whether displacement of the spine was driven to a degree, we used the standard whole skeleton shape model (Open Sim Model), which has a physiological curvature (anterior lordosis), as seen in the pre-tow drawing of Fig. 6 . In addition, the bone part of the spine had a rigid body that does not become deformed, and the disc had an isotropic elastic body (elastic modulus 500 

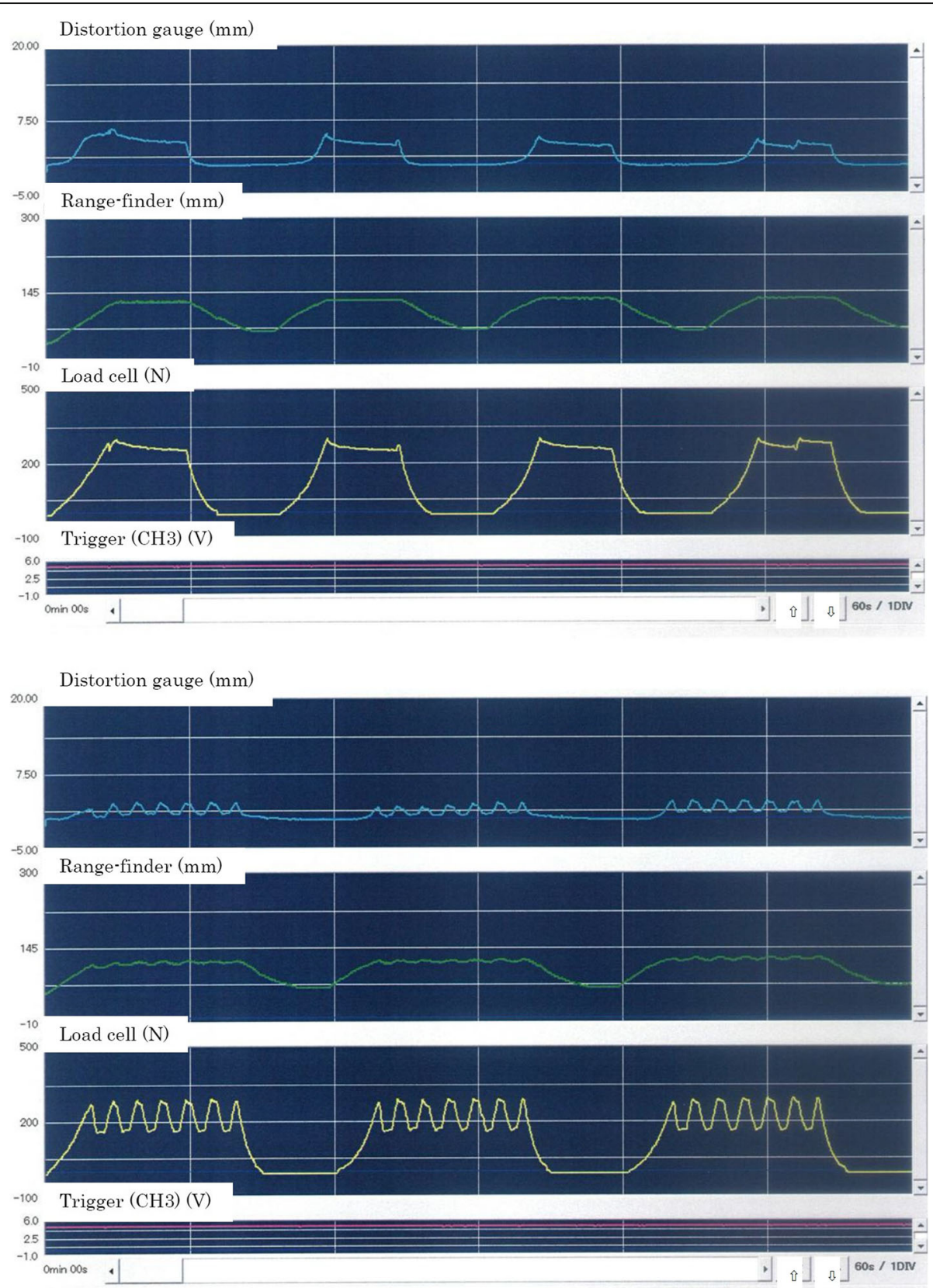

Fig. 5 An example of two different towing patterns. The strain gauge was able to determine the linear response to vibration movement at the skin surface of the lumbar spine

MPa, Poisson ratio 0.3). We ignored any tissue or intervertebral joint actions such as movement of the ligaments surrounding the spine. All deformation of the spine due to towing occurs in the intervertebral disc. Under these conditions, this analysis confirmed the local deformation (intervertebral disc) against the deformation of the entire spinal column, and the result did not affect the magnitude of the elastic modulus of the intervertebral disc.

According to FEM simulation, 3-mm displacement of the lumbar spine region was obtained under $100 \mathrm{~mm}$ of body traction between the holding arm and pelvic girdle belt. The maximum strain value was 0.55 at the L1/L2 intervertebral disc.

\section{Other findings}

Voluntary muscle contraction or movement of the trunk by the participants resulted in turbulence in the traction pattern. Therefore, participants were asked to relax during the experimental period. 
Table 2 Self-report assessment of lumbar traction according to qualitative analysis

\begin{tabular}{lccccc}
\hline & \multicolumn{3}{l}{ Assessment for 3 days } & \\
\cline { 2 - 4 } & Improved & Changeless & Worsened & total \\
\hline Traction A & 78 & 11 & 6 & 95 \\
Traction B & 79 & 12 & 4 & 95 \\
total & 157 & 23 & 10 & 190 \\
\hline
\end{tabular}

Mantel-Haenszel Chi-Square for 2 x r table. $Q_{s}$ (Mean score

statistic) $=0.168, p=0.682$

Both A mode and B mode showed improvement in 78 (82.1\%) and 79 (83.2\%). There was no difference between two modes $(p=0.682)$

\section{Self-report treatment diary}

The coding of diary content emerged in 30 of 64 combinations $(=4 \times 4 \times 4)$. The frequencies of occurrence of these combination in 190 cases were as follows: nnn, 11; nni, 1; nnu, 3; nin, 4; nii, 4; inn, 7; ini, 1; iin, 10; iii, 30; iiu, 3 ; iui, 5 ; iuu, 14; iuw, 1 ; iwi, 1 ; iwu, 2 ; unn, 3 ; unu, 2; uin, 2; uii, 25; uiu, 9; uiw, 1 ; uun, 6; uui, 16; uuu, 19; uuw, 2; uww, 1; wnu, 1; wuu, 1; wwu, 3; and www, 2.
The final judgment of each three-day combination was improved with nnn, nni, nnu, nin, nii, inn, ini, iin, iii, iiu, iui, iuu, iwi, unn, unu, uin, uii, uiu, uun, and uui; unchanged with iwu, uuu, wnu, and wuu; and worse with iuw, uiw, uuw, uww, wwu, and www. Both A mode and B mode showed improvement in 78 (82.1\%) and 79 $(83.2 \%)$ cases (Table 2$)$. There was no difference between the two modes $(p=0.682)$. We confirmed immediate utility or change by lumbar traction, which was compatible with the clinicians' impression in daily practice.

Additionally, there were no cases of stopping and no adverse events.

\section{Discussion}

Despite the long history of use of lumbar traction in clinical practice, the evidence of its effectiveness has not been documented and proved [13]. The Cochrane Database of Systemic Review has indicated that traction may make little or no difference in pain intensity, functional status, and global improvement or return to work when compared to

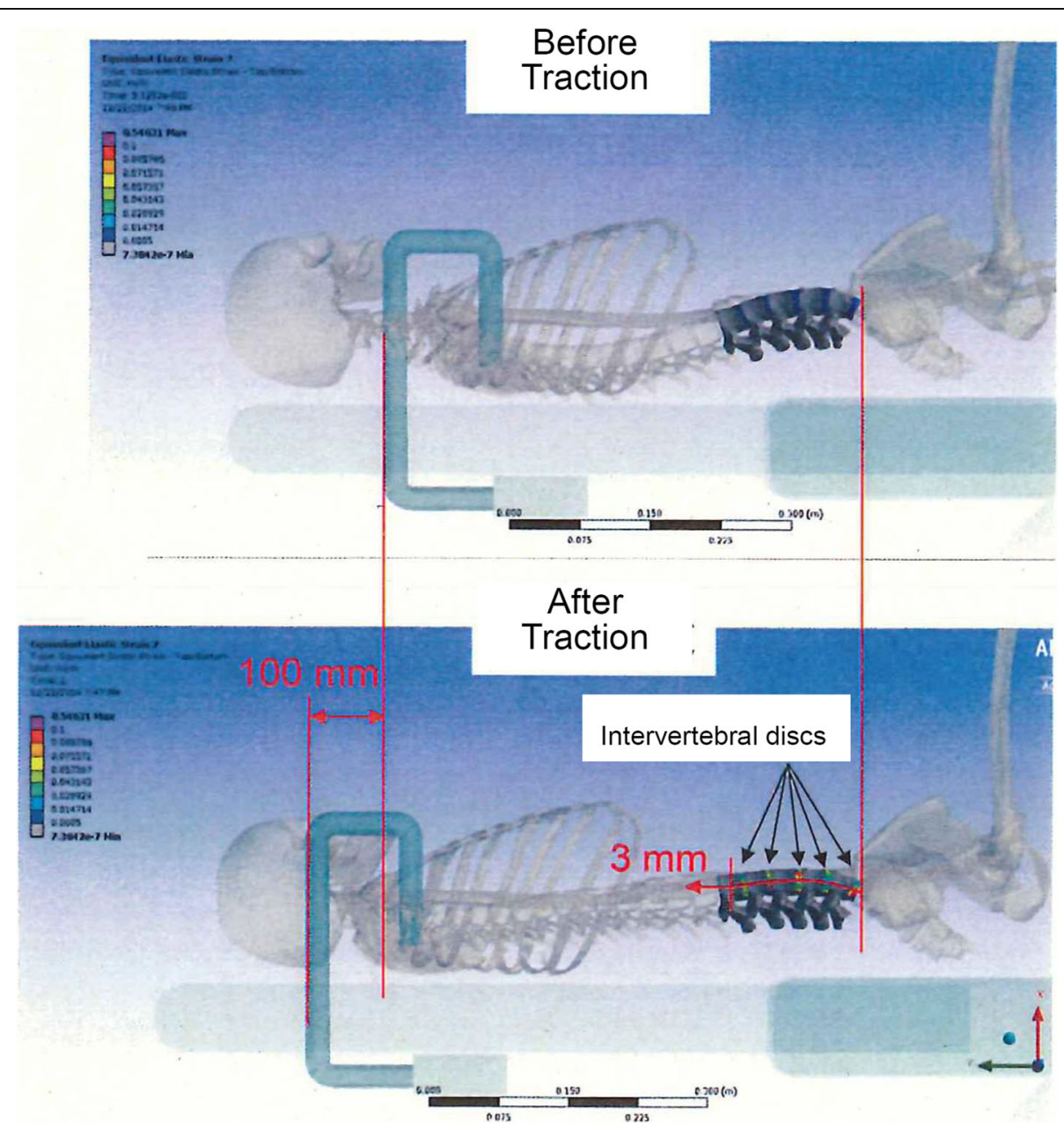

Fig. 6 Finite element modeling. Under finite element method simulation, 3-mm displacement of the lumbar spine region is obtained under 100 $\mathrm{mm}$ of body traction between the holding arm and pelvic girdle belt. The maximum strain value is 0.55 at the L1/L2 intervertebral disc 
placebo, sham traction, or no treatment $[4,6]$. To date, the use of traction as treatment for non-specific LBP is not supported by the best available evidence.

\section{Interpretation of the current experiment}

(1) The concept of traction device used in the current study is a link between the upper and lower body segments, which are connected by the lumbar spine. The upper body unit holds the body with holding arms, and the lower body one, which moves on the rail, provides the constant distraction force regulated by the computer against stress relaxation of human tissue. Subsequently, the device is uniformly able to provide machinedelivered traction to the lumbar spine with minimal lordosis. The reasons for the controversial results of the effectiveness of lumbar traction are mainly derived from the lack of availability to maintain constant interventional procedures with a conventional traction device. These potential factors include positioning of the participant, application method of the distraction force, and, sequentially, the lack of confirmation of mechanical loading. With newly developed traction devices, we can more readily measure variables or control these factors.

(2) In this study, we qualitatively documented the distraction at the lumbar spine with reproducibility, although the accuracy of the strain gauge on the lumbar skin was not quantitatively sufficient to identify the fine movement of the pelvic traction device. Although distance measurement on the body surface has been considered difficult until now [14], the qualitative aspect on a drawing chart was reasonably supportive for our research.

(3) The current experiment was the first stage of our project to examine the effect of lumbar traction. In the next stage, a randomized controlled trial of lumbar traction based on patient-centered outcome and the results of available traction conditions will be needed. The effectiveness of lumbar traction should be evaluated in a combination of a biomechanical study, FEM simulation, and clinical trial.

(4) We could obtain a rough figure of shifting distance at the lumbar spine using FEM simulation.

However, the validity of the calculated figure should be checked in a future experiment.

\section{Our current research direction}

In this study, we wanted to clarify whether lumbar traction is clinically effective in reducing LBP and determine how lumbar traction affects the body of patients with LBP (mechanism). Given the hesitation to use traction, we first sought to determine the clinical effectiveness even in a subgroup of patients rather than identifying the mechanism of action. After establishing clinical utility, we think it is possible to quantitatively examine the mechanism of action of lumbar traction. According to the system control theory, transfer function provides specific characteristics of the targeted system, which is the lumbar spine in this case. Between input as a loading force and output as a distractive distance, we calculated TS. Even after demonstrating the reproducibility of the traction procedures, we still face the lack of a "good" control (placebo, sham, or null) for lumbar traction that is clinically relevant.

\section{Bridging the gap to clinical effectiveness}

Several previous studies have attempted to assess the biomechanical changes to the lumbar spine, particularly the height of discs, following the lumbar traction procedure [15-17]. Furthermore, researchers have eagerly sought a precise measuring method to detect the changes, including in degenerative models [18-20]. However, even after confirming mechanical loading, there may be variations in the responsiveness of patient groups. Previously, researchers have shown such variations in responsiveness to lumbar traction [10,11, 21].

By combining the results of a clinical study and FEM simulation, we could confirm some mechanical actions at the lumbar spine in the current study. We have already prepared some measurement scales for clinical evaluations that have already undergone psychometric standardization $[4,12,22,23]$. If we include the clinical effectiveness of lumbar traction in a well-designed clinical trial, it is possible to have sufficient evidence of the effectiveness of lumbar traction based on the current biomechanical study. Actual loading patterns or the manner in which the lumbar spine experienced loading should be investigated after determining clinical effectiveness.

In this study, we added vibrating force to the preload (corresponding to $40 \%$ of the body weight) because some prior articles have reported the usefulness of vibration on LBP, and we think that increasing sensory input could have a positive effect $[24,25]$.

\section{Study limitations}

Identifying an appropriate loading mode may still be an essential step for ascertaining the clinical utility of lumbar traction. The measurement of distraction distance itself simply relies on a computer simulation conducted by FEM. We only assessed the distance on the lumbar skin and did not directly assess the shift of discs or vertebral bodies. However, the distraction load is applied through the upper and lower body parts that have moved on the horizontal rail. As the position of the lumbar spine maintains minimal lordosis in each case, shifting distance on the skin parallelly reflects positions of bony elements in deeper layers. 


\section{Conclusions}

The current study, which combined a biomechanical experiment with FEM simulation and analysis of patients' perspective, found that lumbar traction operates as an actual mechanical intervention therapy for patients with chronic LBP, and it provided the possibility of an immediate effect after traction.

\section{Abbreviations}

A/D convertor: analog-to-digital converter; AV: average value; CAD: computer-aided design; Cl: confidence interval; FEM: finite element model; LBP: low back pain; SD: standard deviation; TS: traction stiffness

\section{Acknowledgements}

We thank the orthopedic surgeons, their staff, and the patients who willingly participated in this study. The following clinics that used traction devices participated in this experiment:

Arai Orthopaedic Clinic (MINATO),

Fujino Orthopaedic Clinic (MINATO),

Tanabe Orthopaedic Clinic (MINATO),

Miyake Orthopaedic Clinic (MINATO),

Harada Orthopaedic Hospital (OG), and.

Osada Orthopaedic Clinic (OG).

We also greatly appreciate the following 28 hospitals and clinics that participated in this project:

Akashi Orthopedic Clinic, Arai Orthopaedics Clinic, Chosi Clinic, Fujino Orthopedic Clinic, Fujino Orthopaedics, Harada Orthopedic Hospital, Hasegawa Orthopaedic \& Rehabilitation, lizuka Orthopaedic Clinic, Imazato Inagaki Orthopaedics, Karaki Orthopaedics, Kazusa Orthopaedics, Koike Orthopedic Clinic, Kubota Clinic, Matsuda Orthopedics Clinic, Minezaki Orthopaedic Clinic, Miyake Orthopaedic Clinic, Miyata Clinic, Nakada Hospital, Narashinodai Orthopedics \& Internal Medicine Clinic, Noguchi Hospital, Osada Orthopedic Clinic, Ryusoh Orthopaedic Hospital, Suzuki Orthopaedic Clinic, Tana Orthopedic Clinic, Tanabe Orthopaedic Clinic, Uehara Orthopedic Clinic, Ueno Orthopaedics, and Wada Clinic. Additionally, we thank the following researchers of the laboratory of Biomechanical Design, Faculty of Engineering, Hokkaido University. They helped with part of the finite element model simulation, data analysis, and pilot experiments in our study:

Satoshi YAMADA, Dr. Eng.

Keeratihattayakorn SARAN, Dr. Eng.

Hayato SUZUKI, Dr. Eng., and.

Yumi YAMAZAKI.

\section{Funding}

This study was a joint project of the Japanese Clinical Orthopaedic Association with the Japanese Society for Musculoskeletal Medicine, which contracted with two companies, MINATO Medical Science and OG Wellness Technologies, to conduct a clinical trial in order to assess the clinical utility of lumbar traction treatment (recipient: Hideki Tanabe). The present biomechanical analysis was conducted as part of that clinical trial. The funding provided by these societies and companies mainly served to cover the fees of disposable research supplies, such as strain gauge or electrodes.

\section{Availability of data and materials}

The corresponding author has full access to all data in the study and assumes final responsibility for the decision to submit this manuscript for publication. The datasets used and/or analyzed during the current study, which are maintained by designated researchers, are available through the corresponding author on reasonable request.

\section{Authors' contributions}

ST organized the biomechanical experiment and conducted the finite element model simulation. TA, HT, and KF recruited the participants and measured several parameters in their outpatient clinics. TD and MA performed the data analysis. MA prepared the first draft of the manuscript, and all authors contributed to writing as well as reviewing and approving the final version of the manuscript.

\section{Ethics approval and consent to participate}

All procedures performed in studies involving human participants were conducted in accordance with the ethical standards of the institutional and/ or national research regulations, and with the 1964 Helsinki declaration and its later amendments or comparable ethical standards. Written informed consent was obtained from all participants, and the study protocol was approved by the institutional review board of the Japanese Clinical Orthopaedic Association (approval number: 2015-01).

\section{Consent for publication}

Not applicable.

\section{Competing interests}

The funding body or device providers had no role in the study design, data collection, data analysis, data interpretation, or writing of the manuscript.

\section{Publisher's Note}

Springer Nature remains neutral with regard to jurisdictional claims in published maps and institutional affiliations.

\section{Author details \\ ${ }^{1}$ Division of Human Mechanical Systems and Design, Faculty of Engineering, Hokkaido University, Kita-13, Nishi -8, Kita-ku, Sapporo-shi, Hokkaido 060-8628, Japan. ${ }^{2}$ Tanabe Orthopaedic Clinic, 3-2-16 Narimasu, Itabashi-ku, Tokyo 175-0094, Japan. ${ }^{3}$ Arai Orthopaedic Clinic, 1-19-7 Asumigaoka Midori-ku, Chiba-shi, Chiba 267-0066, Japan. ${ }^{4}$ Fujino Orthopaedic Clinic, 2-15-12 Johoku, Naka-ku, Hamamatsu-shi, Shizuoka 432-8011, Japan. ${ }^{5}$ Geriatric Care Facility Excellent Care Shizu, 1316-1 Kami-Shizu, Sakura-shi, Chiba 285-0846, Japan. ${ }^{6}$ Graduate School, International University of Health and Welfare, 4-1-26 Akasaka, Minato-ku, Tokyo 107-8402, Japan. ${ }^{7}$ Present address: National Institute of Technology, Hakodate College, 14-1, Tokura-cho, Hakodate-shi, Hokkaido 042-8501, Japan. ${ }^{8}$ Present address: Geriatric Care Facilities Tomisato Tokushu-en, 1-1-1 Hiyoshi-dai, Tomisato-shi, Chiba 286-0201, Japan.}

Received: 21 August 2018 Accepted: 28 March 2019

Published online: 09 April 2019

\section{References}

1. Freburger JK, Holmes GM, Agans RP, Jackman AM, Darter JD, Wallace AS, Castel LD, Kalsbeek WD, Carey TS. The rising prevalence of chronic low back pain. Arch Intern Med. 2009;169(3):251-8.

2. Ono R, Yamazaki S, Takegami M, Suzukamo Y, Konno S, Kikuchi S, Fukuhara S. Patient-reported disability in the general Japanese population was associated with medical care visits for low back pain, regardless of pain intensity. J Orthop Sci. 2015;20(4):742-9.

3. Graphical Review of Japanese Household, from Comprehensive Survey of Living conditions. 2013. Available at: http://www.mhlw.go.jp/toukei/list/dl/ 20-21-h25.pdf Accessed June 29, 2018.

4. Guzman J, Esmail R, Karjalainen K, Malmivaara A, Irvin E, Bombardier C. Multidisciplinary bio-psycho-social rehabilitation for chronic low back pain. Cochrane Database Syst Rev. 2002;1:CD000963.

5. Schimmel JJ, de Kleuver M, Horsting PP, Spruit M, Jacobs WC, van Limbeek J. No effect of traction in patients with low back pain: a single Centre, single blind, randomized controlled trial of intervertebral differential dynamics therapy. Eur Spine J. 2009;18(12):1843-50.

6. Wegner I, Widyahening IS, van Tulder MW, Blomberg SE, de Vet HC, Brønfort G, Bouter LM, van der Heijden GJ. Traction for low-back pain with or without sciatica. Cochrane Database Syst Rev. 2013;8:CD003010.

7. Harte AA, Gracey JH, Baxter GD. Current use of lumbar traction in the management of low back pain: results of a survey of physiotherapists in the United Kingdom. Arch Phys Med Rehabil. 2005;86(6):1164-9.

8. Madson TJ, Hollman JH. Lumbar traction for managing low back pain: a survey of physical therapists in the United States. J Orthop Sports Phys Ther. 2015; 45(8):586-95.

9. Diab AA, Moustafa IM. The efficacy of lumbar extension traction for sagittal alignment in mechanical low back pain: a randomized trial. J Back Musculoskelet Rehabil. 2013;26(2):213-20.

10. Fritz JM, Thackeray A, Childs JD, Brennan GP. A randomized clinical trial of the effectiveness of mechanical traction for sub-groups of patients with low 
back pain: study methods and rationale. BMC Musculoskelet Disord. 2010;11:81.

11. Thackeray A, Fritz JM, Childs JD, Brennan GP. The effectiveness of mechanical traction among subgroups of patients with low back pain and leg pain: a randomized trial. J Orthop Sports Phys Ther. 2016;46(3):144-54.

12. Shirado O, Doi T, Akai M, Fujino K, Hoshino Y, Iwaya T. An outcome measure for Japanese people with chronic low back pain: an introduction and validation study of Japan low Back pain evaluation questionnaire. Spine. 2007;32(26):3052-9.

13. [No authors listed]. Mechanical lumbar traction. What is its place in clinical practice? J Orthop Sports Phys Ther. 2016;46(3):155-6.

14. Frost M, Stuckey S, Smalley LA, Dorman G. Reliability of measuring trunk motions in centimeters. Phys Ther. 1982;62(10):1431-7.

15. Kurutz M. In vivo age- and sex-related creep of human lumbar motion segments and discs in pure centric tension. J Biomech. 2006:39(7):1180-90.

16. Park WM, Kim K, Kim YH. Biomechanical analysis of two-step traction therapy in the lumbar spine. Man Ther. 2014;19(6):527-33.

17. Simmerman SM, Sizer PS, Dedrick GS, Apte GG, Brismée JM. Immediate changes in spinal height and pain after aquatic vertical traction in patients with persistent low back symptoms: a crossover clinical trial. PM R. 2011;3(5): 447-57.

18. Chow DHK, Yuen EMK, Xiao L, Leung MCP. Mechanical effects of traction on lumbar intervertebral discs: a magnetic resonance imaging study. Musculoskelet Sci Pract. 2017;29:78-83.

19. Lai A, Chow DH. Effects of traction on structural properties of degenerated disc using an in vivo rat-tail model. Spine. 2010;35(14):1339-45.

20. Lee RY, Evans JH. Loads in the lumbar spine during traction therapy. Aust J Physiother. 2001;47(2):102-8.

21. Cai C, Pua YH, Lim KC. A clinical prediction rule for classifying patients with low back pain who demonstrate short-term improvement with mechanical lumbar traction. Eur Spine J. 2009;18(4):554-61.

22. Deyo RA, Battie M, Beurskens AJ, Bombardier C, Croft P, Koes B, Malmivaara A, Roland M, Von Korff M, Waddell G. Outcome measures for low back pain research. A proposal for standardized use. Spine. 1998;23(18):2003-13.

23. Suzukamo Y, Fukuhara S, Kikuchi S, Konno S, Roland M, Iwamoto Y, Nakamura T. Committee on science project, Japanese Orthopaedic association. Committee on science project, Japanese Orthopaedic association. Validation of the Japanese version of the Roland-Morris disability questionnaire. J Orthop Sci. 2003;8(4):543-8.

24. Stokes IA, Gardner-Morse M. A database of lumbar spinal mechanical behavior for validation of spinal analytical models. J Biomech. 2016;49(5):780-5.

25. Wang S, Wang L, Wang Y, Du C, Zhang M, Fan Y. Biomechanical analysis of combining head-down tilt traction with vibration for different grades of degeneration of the lumbar spine. Med Eng Phys. 2017;39:83-93.

Ready to submit your research? Choose BMC and benefit from:

- fast, convenient online submission

- thorough peer review by experienced researchers in your field

- rapid publication on acceptance

- support for research data, including large and complex data types

- gold Open Access which fosters wider collaboration and increased citations

- maximum visibility for your research: over $100 \mathrm{M}$ website views per year

At BMC, research is always in progress.

Learn more biomedcentral.com/submissions 